\title{
The Potential Ecological Risk of Pb for Multi-phase Medium of Artificial Reefs
}

\author{
Yubo Dong ${ }^{1}$, YuanYuan Dai ${ }^{2 *}$ and Kefeng Liu ${ }^{2}$ \\ ${ }^{1}$ Fisheries Research Institute of Tianjin Tianjin, China \\ ${ }^{2}$ Tianjin Bohai Sea Fisherise Research Institute Tianjin, China \\ ${ }^{*}$ Corresponding author
}

\begin{abstract}
Using ICP-MS to detect $\mathrm{Pb}$ in the multi-phase mediumin the artificial reef .The results showed that: $\mathrm{Pb}$ of sediment is varied from $0.138 \sim 0.470 \mathrm{mg} / \mathrm{Kg}$, mean $0.273 \pm 0.106 \mathrm{mg} / \mathrm{Kg}$,The sediment distribution of $\mathbf{P b}$ decreased in the order: lower $>$ middle $>$ upper layer in each station. Risk evaluation showed that potential ecological risk index of $\mathrm{Pb}$ is low in the reef sediments; accumulate partial index is belong to moderate pollution levels; enrichment factor is belong to the light pollution-free . Pb of organisms is rang from 0.004-0.519 $\mathrm{mg} / \mathrm{Kg}$, mean $0.185 \pm 0.170 \mathrm{mg} /$ Kgin reef area; $B C F$ value of $\mathbf{P b}$ in organisms is generally higher than $B A F$ value; its health risk factor is far less than 1 , indicating that $\mathrm{Pb}$ has no obvious health risks on exposure population.
\end{abstract}

Keywords-heavy metals; spatial distribution; ecological risk assessment

\section{INTRODUCTION}

Artificial reef areas is a special ecosystem, according to the survey, at the end of artificial reefs are three main types of quality concrete reefs serve different sediment after the dissolution of the hydration products if there are certain rules? Past, researchers concentrated on the surface sediments vertical distribution and pollution situation of heavy metals, Speciation and bioavailability, geochemical characteristics and influencing factors were studied ${ }^{[1-9]}$. But on the studies of heavy metals distribution of the multiphase medium in artificial reef rarely reported, based on this, the paper of heavy metals in artificial reef about multi-phase medium (sediments and organisms) in preliminary accumulation of $\mathrm{Pb}$ and other aspects of ecological risk to the reef area of scientific understanding of heavy metal pollution and its environmental safety for the protection of aquatic ecological effects of the area's ecological safety, scientific development and management of biological resources and the prevention and control risks provide a scientific basis.

\section{MATERIALS AND METHODS}

\section{A. Sample Collection and Determination}

Artificial reef areas selected for the survey area (Figure 1), in which the station is located in the $20101,2,3$ vote reef; 4,5,6 stations located in 2012 voted reef; stations 7,8,9 located in 2014 voted reef; nine were selected sampling stations. Field survey of all processes in strict accordance with "marine monitoring" (GB/T12763.6-2007) [10] carried out the job. Sediments and Synechogobius ommaturus (Richardson) in artificial reef as the object, after dissection, take the muscle was freeze-dried, and then by microwave digestion and then measured on the machine.

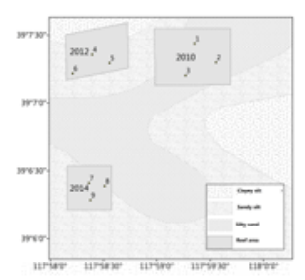

\section{FIGURE I. SAMPLING SITES IN ARTIFICIAL REEFS}

B. Potential Ecological Risk Index

$$
\begin{aligned}
& C_{f}^{i}=C_{o}^{i} / C_{n}^{i} \\
& E_{r}^{i}=T_{r}^{i} \times C_{o}^{i} / C_{n}^{i}
\end{aligned}
$$

Cio is the measured content of heavy metals in sediments; $C_{n}^{i}$

$T_{r}^{i}$ (Pb toxicity response parameters were 5); wherein the for the calculation of the required reference value $(\mathrm{Pb} 70)$; potential ecological risk of heavy metal pollution index and the hierarchical relation in Table 1.

TABLE I. HEAVY METAL POLLUTION INDEX AND POTENTIAL ECOLOGICAL HARM HIERARCHICAL RELATION

\begin{tabular}{cc}
\hline$E_{r}^{i}$ & Ecological Risk \\
\hline$E_{r}^{i}<40$ & low \\
$40 \leq E_{r}^{i}<80$ & intermediate \\
$80 \leq E_{r}^{i}<160$ & Heavier \\
$160 \leq E_{r}^{i}<320$ & weight \\
$E_{r}^{i} \geq 320$ & serious \\
\hline
\end{tabular}

C. Accumulate Index

$$
I_{\text {geo }}=\log _{2}\left(C_{n} / 1.5 B_{n}\right)
$$


$\mathrm{Cn}$ is the measured content of heavy metals in sediments of $\mathrm{n}(\mathrm{mg} / \mathrm{kg}) ; \mathrm{Bn}$ is geochemical background value of the element $(\mathrm{mg} / \mathrm{kg}), \mathrm{Pb} \mathrm{25} ; 1.5$ for the elimination of sediment diagenesis caused by natural effects of changes in the value of the background and the use of a correction coefficient matrix [11]. According Igeo value of heavy metal pollution will be divided into seven grades, as shown in Table 2.

TABLE II. INDEX OF GEOACCUMULATION AND CLASSIFICATION OF POLLUTION DEGREE

\begin{tabular}{cccccccc}
\hline$I_{\text {geo }}$ & $\leq 0$ & $0 \sim$ & $2 \sim 3$ & $3 \sim 4$ & $4 \sim 5$ & $>5$ \\
\hline series & 0 & 1 & 2 & 3 & 4 & 5 & 6 \\
Degree No Mild & $\begin{array}{c}\text { Partial } \\
\text { Moderate }\end{array}$ & Moderate & $\begin{array}{c}\text { Lay particular } \\
\text { stress }\end{array}$ & serious & $\begin{array}{c}\text { Very } \\
\text { heavy }\end{array}$ \\
\hline
\end{tabular}

\section{Fish Health Risk Assessment}

USEPA established objective risk evaluation system (THQ), evaluation of exposure to chemical pollutants on the population exposed to potential hazards that may exist THQ as a non-cancer risk assessment system, if the result of the calculation is greater than 1 , indicating that the population may be exposed hazards; less than 1 indicates that there is no hazard to exposed populations affect ${ }^{[12]}$.

$$
T H Q=\frac{E_{F} \times E_{D} \times F_{I R} \times C}{R_{F D} \times W_{A B} \times T_{A}} \times 10^{-3}
$$

$E_{F}$ is exposed frequency (365days / year); $E_{D}$ is the time period of exposure is generally the average human life span (70years); $\mathrm{F}_{\mathrm{IR}}$ exposed fish consumption amount of people ( $\mathrm{g} /$ person/day); $\mathrm{C}$ for the heavy metals in fish the actual content $(\mathrm{mg} / \mathrm{kg})$; RFD oral reference dose; WAB is the average body weight $(\mathrm{kg})$; TA non-carcinogenic average exposure time (365days /year $\times \mathrm{ED})$.

\section{E. $Q C$}

The accuracy of the test method is close to $10 \%$ within a $95 \%$ confidence level, the standard material recovery of $90 \%$.

\section{F. Statistics and Analysis}

All data are used Excel for data processing; SPSS10.0 statistical analysis; GraphPad Prism6and ArcGIS cartographic.

\section{RESULTS}

\section{A. Distribution of $\mathrm{Pb}$ in Sediments of the Reef and Its \\ Accumulation Characteristics}

The sediment $\mathrm{Pb}$ of the vertical and horizontal distribution area in Figure 2. Range reef sediments $\mathrm{Pb}$ of 0.138 $0.470 \mathrm{mg} / \mathrm{Kg}$, mean $0.273 \pm 0.106 \mathrm{mg} / \mathrm{Kg}$;. The highest average content of $\mathrm{Pb}$ sediment appears in the 8th station, sandy silt bottom quality; the lowest value of station No. 2, silty sand sediment. Reef sediment vertical distribution shown in Figure 2 (A): lower $>$ middle $>$ upper layer.

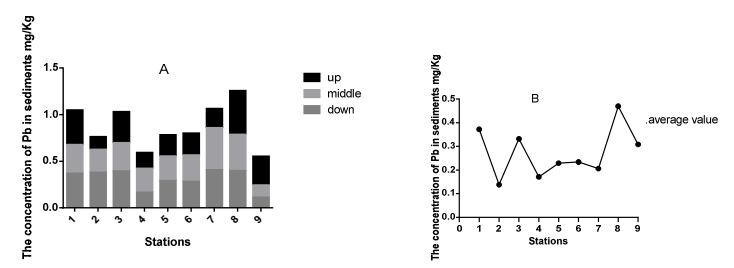

FIGURE II. THE DEPOSITS VERTICAL (A) AND HORIZONTAL DISTRIBUTION (B) OF PB IN SEDIMENTS （MG/KG）

Potential ecological risk index is a low ecological risk; accumulate partial index belong to moderate pollution levels; reef sediment enrichment factor belonging to no light pollution. Reef enrichment factor is far less than 1.5, indicating that the main reef is a natural role.

\section{B. Reef organisms Pb Content Distribution and Risk Assessment}

Reef zone range organism $\mathrm{Pb}$ content is 0.004-0.519 $\mathrm{mg} / \mathrm{Kg}$, average $\quad 0.185 \pm 0.170 \mathrm{mg} / \mathrm{Kg}$. Figure 3 shows, organisms $\mathrm{Pb} \mathrm{BCF}$ is generally higher than the value of $\mathrm{BAF}$, $\mathrm{BCF}$ value difference nine stations were significantly $(\mathrm{P}<0.05)$, the maximum in 7 stations, the lowest value appears in the No. 1 station; each station BAF values were not significant $(\mathrm{P}>0.05)$, the same trend.

According to USEPA standards ${ }^{[12]}$, an oral reference dose $\mathrm{RFD} \mathrm{Pb}$ element is $0.004 \mathrm{mg} / \mathrm{kg} /$ day. The average adult body weight $\mathrm{WAB}$ is $60 \mathrm{~kg}$. The average daily amount of fish for human consumption is $36 \mathrm{~g}$. The health risk factor of $0.005, \mathrm{~Pb}$ is much less than 1 , indicating that $\mathrm{Pb}$ exposed populations had no significant health risk.

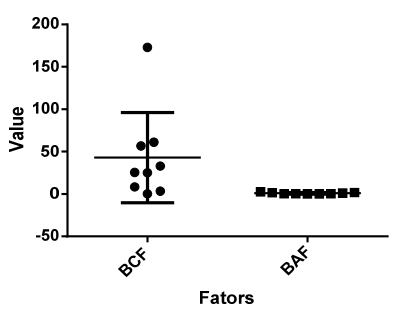

FIGURE III. THE BCF AND BAF OF PB IN ARTIFICIAL REEFS

\section{DISCUSSION}

\section{A. Ecological Risk of Pb in Sediments Reef}

About ecological risk of heavy metals in surface sediment study more ${ }^{[1-3]}$, the distribution of heavy metals in sediments due to the effect of hydrodynamic conditions, sediment particle size, organic matter in sediments and biological factors having differences, which so that different regions of the heavy metals also differences in the spatial distribution ${ }^{[11]}$.

In coastal and estuary waters affected by tides, storms, ocean currents and coastal engineering facilities, the complex pattern of sediment transport, and vary in each estuary area. Surface sediments under the influence of tidal water power and other factors can easily make the surface sediments, especially fine particulate matter resuspension occurs ${ }^{[13]}$. As a result, on the one hand binds to heavy metals in sediments are released, that is, the sudden release of accumulated sediment 
and pollutants; on the other hand, re-suspended fine particulate matter was brought water to other waters, heavy metals in more deposits over a wide range of reallocation.

In this study, sediment $\mathrm{Pb}$ is less than the average of each Sediments 2-3 orders of magnitude, indicating reefs $\mathrm{Pb}$ are within safe limits, sediments cleaner, lighter ecological harm, no enrichment, not the local waters ecosystem impact, this result and other findings are similar to the average of Liu. X. and blue waters of flood and other studies, although $\mathrm{Pb}$ is greater than the present study, but the results did not show $\mathrm{Pb}$ enrichment.

The results of each resulting difference may be related to the investigation area, investigation time, sample pretreatment method, select the value of the background and other factors, therefore, the investigation should strictly follow the "quality of marine sediments" (GB18668-2002) ${ }^{[14]}$ carried out in order to provide basic data for marine sediment quality criteria.

\section{B. Human Health Risk Assessment of Heavy Metals $\mathrm{Pb}$}

Goby is a fish benthic life camp, small-scale activity, contaminant levels in the body to some extent, reflect the pollution status of habitat ${ }^{[11-12]}$. According to the National Aquatic pollution-free food toxic harmful substances NY5073-2001 [24] and fresh marine fish quality standards GB / T $18108-2008{ }^{[15]}(\leq 0.5 \mathrm{mg} / \mathrm{kg})$, this study tailed goby abdominal muscles the average content of $\mathrm{Pb}$ in addition to 7 stations exceeded $3.8 \%$, the rest of the station $\mathrm{Pb}$ content is not exceeded, indicating that the reef area Bonasa belly goby basically meet the quality requirements of aquatic products, but heavy metal contamination of marine coastal affect the quality of fishery products should cause some concern. This Anritsu will wait ${ }^{[3]}$ Wild multiplexing different goby $\mathrm{Pb}$ exceeded a result, human activities more frequently, so there are some differences in this study.

Aquatic organisms including fish is mainly absorbed through the gills and intestines of heavy metals in the water environment, and then transferred to other parts of the body such as the liver and muscle, and the exposure time and the environment is directly related to the dose of exposure ${ }^{[11]}$. Taking into account the goby are short growth type of fish (about 1a born), the paper Madarao belly goby muscle levels of heavy metals may reflect the recent heavy metal contamination of its habitat in accordance with the formula to get its health risk factor of 0.005 , much less than 1 , indicating that $\mathrm{Pb}$ exposed population without health risks. Investigation of heavy metal pollution risk another indicator that metallothionein levels, a biomarker that reflects the combined effect of the environment ${ }^{[3]}$, can be used for early warning of potential ecological risk of heavy metals in sediments, Anritsu will wait ${ }^{[3]}$ Research Complex goby liver metallothionein levels tended to increase, and with the potential risks of heavy metals in sediments consistent index. Given the reliability of the technical means, this topic will be further research in the indicators, with a view to evidence previously discussed.

\section{ACKNOWLEDGEMENT}

This research was financially supported by Fishery Bureau of Tianjin Youth Science and Technology Innovation Project (J-2014-08).

\section{REFERENCES}

[1] Zhang Shuna, Tangjing Chun Tianjin potential ecological risk of heavy metals in sediment Risk Assessment $[\mathrm{J}]$ Marine Science Bulletin .2008,27 (2): 85-90.

[2] Zhang Xiao Long, Ding Dewen, Alex sound, and other western Bohai Sea estuary intertidal zone of heavy metals in seawater and sediments [J] Journal of East China University of Technology: Natural Science Edition .2010,33 (3): 276-280.

[3] An legislature, Cheng Bing-hui, Zhang Lei, Bohai Bay and other estuaries on heavy metal contamination and potential ecological risk assessment [J] China Environmental Science .2010,30 (05): 666-670.

[4] Scythian rock, Song Jinming, Li Xue-Gang, and other heavy metals in various forms of Bohai Bay and geochemical characteristics and environmental significance $[\mathrm{J}]$ Agricultural Environmental Science .2011,30 (12): 2560-2570.

[5] Huosu Xia. Distribution of heavy metals in the sediments and Ecological Risk of [D]. China Ocean University .2011, doctoral dissertation.

[6] Jianghong You, Liu Yang Tianjin coastal seawater contamination by heavy metals and Distribution [J] .2012 Information Science and Technology, (26): 135-137.

[7] Zhang Yan, Luxue Jiang, Liu Honglei, Bohai Bay and other segments of heavy metals in surface sediments Tianjin Distribution and source apportionment [J] Environmental Sciences, 2014, 27 (6): 608-614.

[8] Blue first flood, honey Beibei, Lee Hui, other eastern Bohai Sea and northern Yellow Sea Distribution of heavy metals in sediment [J] China Environmental Science .2014, (10): 2660-2668.

[9] Wanghui Yan sediments geochemical study of Bohai Bay [D]. Chinese Academy of Geological Sciences, 2014.

[10] State Oceanic Administration, marine monitoring GB / T 12763.6-2007 [S] Beijing: China Standard Press.

[11] Heavy Metal Pollution Liu Jinhu multiphase media. Laizhou Bay and its transfer and biological food chain (network) amplification [D]. Institute of Oceanology, 2013.

[12] Zhang to Lancang River water and sediment and heavy metals in fish distribution and ecological risk assessment [D]. Yunnan University, 2015.

[13] Chunhua, Wang square estuary behavioral characteristics of heavy metals in seawater [J] Oceanography: Chinese edition, 1999 (1): 41-47.

[14] State Oceanic Administration of marine sediment quality standards GB 186682-2002 [S]. Beijing: China Standard Press.

[15] Administration of Quality Supervision, Inspection and Quarantine of People's Republic of China. Fresh sea fish quality standards GB / T 18108-2008 [S].Beijing: St

[16] andardization Administration of China. 